\title{
Green Research based on Cultural Three-Hierarchy Theory
}

\author{
Hongquan Li \& Houhog Jin \\ Sports Economics and Management School, Central University of Finance and Economics \\ Beijing 100081, China \\ E-mail:jinhouzhong@126.com
}

Yongmin Hua, Chuanchuan Kong \& Li Lin

Beijing Sport University, Beijing 100084, China

E-mail:Kcc139@163.com

Received: November 22, 2011

Accepted: April 1, 2011

doi:10.5539/jsd.v4n3p196

Foundation item: the philosophical social science project in Beijing (09BaZh126).

\begin{abstract}
The accumulation of green practice has reached a climax in the circle of Beijing Olympic Games and formed the inner culture connotation with its own characteristics. Based on culture three-hierarchy theory, the article expounds systematically green culture and provides theoretical basis for green practice.
\end{abstract}

Keywords: Green culture, Green values, Green system, Green technology

Currently China is in the process of changing the growth mode from the first industrial revolution into the second industrial revolution which is similar to western countries. Looking from the development history of western industrialized countries, the growth mode after the first industrial revolution was mainly driven by investment and its dominant industries were heavy and light industry, which brought about a series of economic and social problems and environmental pollution. (Xiao, Huanyu \& Chen, Yuzhong. 2003)Particularly, environmental pollution is endangering human existence and development. In face of natural environment problems in the process of industrialization, modernization and urbanization of Chins, we should understand green culture correctly and build reasonable green development mode.

\section{Green culture}

Green is the color of plant kingdom. In the heart of most nations in the world, it stands for life, spring, youth, hope, rebirth, fertile, enrich and quiet(Duan, Baolin \& Wu, Zhenjiang, 1989). Besides, green is also the representatives of prosperity, peace and environmental protection, and common representative color used by ecological environmental organizations. In the second half of the 20th century, with the awareness of human demonstrated actions to natural environment, green enterprises, green products, green consumption, green environment, green trade, green life, green technology, green revolution, green plan, green act, green politics, green investment, green Olympics, green education, sustainable agriculture, ecological awareness, ecological education, ecological tourism, ecological engineering, ecological art, ecological philosophy, ecological ethics, environmental aesthetics and so on began to appear in society. All of the green elements are called green culture (Generalized). Narrowly speaking, green culture refers to the culture marked by green plants created by human beings in order to adapt to environment, including acquisition, hunting culture, agriculture, forestry, urban greening and all plant science(Che, Shengquan. 1998). The article mainly discusses about generalized green culture, which is a kind of reflection of civilization that human beings consciously coordinate the relationship with natural environment.

\section{The contents and structure of green culture}

Culture can be approximately divided into three hierarchical structures including spiritual concept, system and material technology as a whole. Every hierarchy is distinguished from each other because of their different relationships from the whole. The culture of spiritual concept mainly refers to the psychological structure, thinking mode and value system of a society, which is not different from philosophy and ideology, but some substances that have not become philosophic theory in between, and is a kind of culture in depth(Lin, Zhiyou. 
2010). For green culture, it means green values and people's recognition and evaluation about green environmental value. Under the guidance of green values, subjects observe and understand things, analyze and grasp objects, solve problems and formulate strategies. As entire guideline of green culture, the formation of green values is based on various elements such as green knowledge, green habits and so on and reflects specific spirits of times. Green values is the deepest hierarchy of green culture and the most basic value target that green culture pursues, as well as fundamental mark distinguished from other culture, which comprises of the core link of green culture structure.

System culture is the middle layer between values layer and artifacts layer. It delivers their interaction between the core and surface: on the one hand, it brings the changes of surface into the mainstream aspect stimulated by core values; on the other hand, core structure is also affected by the changes of surface. For green culture, it refers to the elementary frame and operation mechanism of social green mechanism formed in the process of historical development under the influence of philosophy theory and ideology. They deliver through the ages, change continuously, rise or fall, long or short. They are neither specific substance, nor abstract unseen things, but a kind of middle-layer culture. System layer is the backbone of the system of green culture mode and basic mark of its existence.

Artifacts culture refers to various and rich green environmental technology system and material conditions, which reflects green lifestyle. They are created by humans and serve for humans, are a kind of surface culture that can be seen and touched. It is created for human life and practice currently while people confront with specific problems about natural environment development. Artifacts layer comprises of the external link of green culture structure.

In general, if green culture is compared to a healthy person, values hierarchy should be its soul, system hierarchy should be its skeleton and artifacts hierarchy should be its flesh and blood. Spiritual concept hierarchy guides the specific application of system hierarchy and artifacts hierarchy. In return, system hierarchy and artifacts hierarchy also provides logic proof and practical support for spiritual concept hierarchy. Three hierarchies distinguish from each other but connect with each other, which comprise of the integrated structure of green culture.

\section{Green development mode}

The participants of green practice are extensive and their behavior is complex. According to three hierarchies structure of green culture, the article systematically considers green development and its construction mode from the construction of green values, green system arrangement and green technology innovation as a whole.

\section{1 the construction of green values}

Recently, especially after holding Beijing Olympic Games successfully, the rise and popularity of green city construction, green production, green consumption and green lifestyle represented by green Beijing, people green awareness and green concept have become stronger and stronger. But generally speaking, it is still in its infancy. Currently China is in the important period of social transformation, which brings dramatic changes into entire social mainstream values and multi-values. The phenomena such as null lofty values, lacking of basic order and lost in rules values that appear in society comprise the real dilemma of green culture development generalization.

Looking from governmental level, realizing green development should build green government and set up viewpoint of green development. Firstly, develop green citizens and build strong public opinion atmosphere. To realize public dissemination of green culture by means of propaganda and education, and call for more extensive public environmental awareness, make people have conscious green, environmental, economic and healthy lifestyle, work style and consumption style. Green development is the specific implementation of green Olympics concept in all aspects. The successful practice of green Olympics lays foundation for green development; secondly, develop green economy; the government and society should set up the viewpoints of green production and green consumption, create conditions and atmosphere to encourage the growth of green entrepreneurs, develop green productivity, create green GDP, save energy and reduce emission, protect environment, seek for economic growth, and sustainable usage of green ecology and resources, as well as the improvement of environmental quality, and realize harmonious development of human, society and nature.

\subsection{Green system arrangements}

Green system refers to various system arrangements surrounding sustainable development. In general, sustainable development refers to the development that meets human needs, without compromising the needs of future generations(WCED, 1987). From the construction of green system in 1960s to now, the development at 
home and abroad has experienced from traditional green system stage to modern green system stage, but it is still not mature and needs innovation.

Green system innovation should emphasize on the perfection of system firstly. The government build administrative organizations, through formulating green standards, laws, provisions, policies and regulations, strictly enforce according to the laws by enforcement organizations to restrict organizational and individual environmental deeds. For example, take the emission of life trash of inhabitants as standards to charge garbage collection. Secondly, it is necessary to set up a set of scientific green operation mechanism, to ensure that each link such as the stimulation, implementation, supervision and accomplishment of related green laws and policies carries out effectively and systematically. Finally, the formation and operation of social green system also needs support of entire strong social atmosphere. Because, no matter how it is, the main body who finally finishes green practice is the entitative individual, including specific practitioner of green behavior and operator of green system operation, whose initiatives are the key to the success of entire green plan.

\subsection{Green technology innovation}

Green technology is the important tendency of technological development in 21 century, and a technology strategy implemented by a country in order to realize economic sustainable development, whose target is to return to the nature and protect natural resources and ecological environment. Green technology extensively refers to all tools, methods and means that aim to prompt sustainable development. It is a weapon that people carry out green revolution. Only from the perspective of science and technology, green technology approximately is divided into two categories: one is science and technology that is used for recovering the environment and ecology that is being damaged or have been damaged, for example, sewage, trash treatment technology; the other is beneficial science and technology people applies to protect ecological and natural environment in social life and production process, for example, the technology that uses water or wind for power generation is more environmental than that uses coal.

The development of modern technology must be dedicate to green practice, make great effects to reduce the negative influence of human activities on environment and ecology and prompt harmonious development between humans and nature. Firstly, continuously innovate green technology as many as possible, perfect green technology system; secondly, reduce green technology cost, apply advanced green technology generalization to specific operation of green environmental practice. People should have awareness of protecting environment in the process of production and in their lives, do deeds that are conductive to ecological environment without pollution. Secondly, protect environment, supervise pollution and implement deed of protecting environment.

\section{Conclusions}

Based on healthy and perfect green system, guided by the government, by means of green technology, operated by social organizations, taken public positive participation as the premise and guarantee, and mutual cooperation with each other as operation mode, a new civilization — green civilization marked by environmental protection is set up.

\section{References}

Che, Shengquan. (1998). Green Culture. Environment Review. 1998, Vol. 4, pp. 4.

Duan, Baolin \& Wu, Zhenjiang. (1989). Grand World Folk. Peking University Press , 1989.1.

Li, Yangyu. (2003). Research on green technology and its support system. 2003, 4.

Lin, Zhiyou. (2010). Three levels of Marxism combined with three stages of Chinese traditional culture. 2010, 1.

WCED. (1987). Our common future. 1987, 4.

Xiao, Huanyu \& Chen, Yuzhong. (2003). Exploration and Analysis of New Idea of Harmonious Development of Human Society and Olympics--Explanation of the three themes of Beijing Olympic Games. Journal of Shanghai University of Sport. 2003, Vol. 2, 10-11. 